\title{
Emotions in Linguistic Behaviour
}

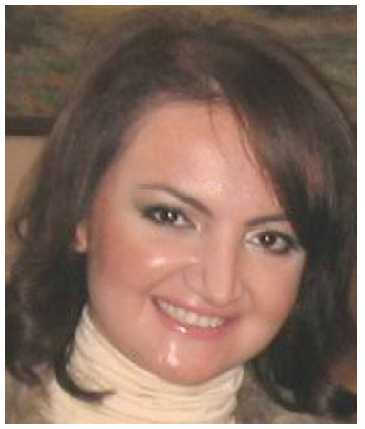

Anna Rostomyan

\author{
When dealing with people, remember \\ you are not dealing with creatures of \\ logic, but creatures of emotion.
}

Dale Carnegie

B eing humans we always experience some sort of emotion or feeling. Moreover, our emotional state varies throughout the day depending on what happens to us and on the stimuli that we perceive. However, we may not always be conscious of it; we may not know or express with clarity which emotion we are experiencing in a given moment. The experience and expression of emotions comprise a routine, yet extraordinarily complex and influential facet of the human experience, particularly in the realm of interpersonal communication.

V.J. Wukmir states that emotion is an immediate answer of the organism that informs about the degree of favourability of the perceived situation. ${ }^{1}$ If it seems to favour its survival, the living being experiences both positive (happiness, satisfaction, peace, etc.) and negative (grief, sorrow, horror, etc.) emotions when the situation seems to be unfavourable for its survival. All living beings have this mechanism of emotion which guides them all the time, acting as a compass, to find favourable situations to survive (those which produce positive emotions) and to move away from those which are thought to be unfavourable for survival (which produce negative emotions). This emotional appraisal is carried out by means of many diverse physico-chemical mechanisms depending on the complexity of the organism. The elaboration of the emotions is an involuntary process, of which one can only be partially conscious. It is true that we often speak about emotional control or about controlling the emotions as a necessary ability for successful social relationships. Nevertheless, it should be mentioned that we do not have control about the emotion itself and we can just control its external manifestation (Wukmir 1967).

Based on the overall findings of our study on emotions, we have come to think that, although the list of feelings and reactions we include under the term emotion is almost infinite, generally the great variety of emotions in our emotional repertoire can be classified into two opposite poles: positive vs. negative, which are reflected respectively in our everyday speech. In their book "Principles of Communication and Emotion in Social Interaction" Andersen and Guerrero assert that although there may be slight differences in how positive or negative emotions are viewed in particular situations, they generally tend to have either positive or negative reputations (Andersen and Guerrero 1998). ${ }^{2}$

We have revealed that the problem of emotion involves a number of important issues: perception, processing and evaluation of emotions and emotional states; verbal and nonverbal means of expressing emotion. Facial expressions, together with bodily movements 
form non-verbal means of communicating the emotional state of the speaker. Since emotions find their verbalization in our everyday speech, they are reflected consequently in speech acts having positive or negative implications. It is true that emotions are very complex experiences and when expressing them, we use a great variety of words and word combinations to express them. Nonetheless, we could use all the words of a dictionary to express different emotions and still lack the ability of expressing the actually felt emotion in an accurate way. Therefore, due to the infinite extension of emotional phenomena, it is impossible to make a full description of all the emotions that we can experience. The complexity of the phenomenon makes the impression that we always lack words to describe our emotions accurately. But under this complexity, there is a common factor typical of all emotions: each emotion expresses a quantity or magnitude on a positive/negative scale. In this way, we experience positive and negative emotions in different degrees and with diverse intensity. We can experience abrupt or gradual changes of emotional intensity, towards either the positive or negative side. That is to say, all emotions represent a magnitude or measurement along a continuum that can take positive or negative values. In everyday language we express our emotions with a positive/negative scale and in variable magnitudes with the help of different means of emotive emphasis, such as I feel quite well, I feel well, I feel very well (showing degrees for positive emotions) or I feel quite bad, I feel bad, I feel very bad (showing degrees for negative emotions).

According to the situation in which a certain emotion is aroused, we choose words such as love, friendship, fear, uncertainty, respect, etc., that, at the same time, show the emotional sign (positive or negative). And according to the intensity of the emotion we choose words like quite, awfully, enough, very, etc., and, in this way, we compose the description of emotions. We say, for example, I feel very well understood (positive) or I feel a little depressed (negative). As a result, we can recognize two well differentiated components in all emotions. On the one hand, there is a qualitative component that is expressed by means of the word that we use to describe the emotion (love, friendship, fear, insecurity, etc.) determining the "positiveness" or "negativeness" of the emotional sign. On the other hand, all emotions possess a quantitative component that is expressed by means of words of magnitude (little, quite, enough, a lot, great, some, much, etc.).

It is generally believed that emotion plays the role we expect it to, i.e. communicating information about our internal states, feelings, beliefs and desires (Goleman 1995; Murray 1964). However, in some circumstances we observe that emotions are not demonstrated so explicitly in speech or just vice verse: sometimes people tend to sound more emotional so that to have an impact on the interlocutors and thus to achieve their desired communicative goal. Besides, when undergoing very strong emotions the speakers are not able to control them or to try to minimize the degree of the felt emotion, and consequently, the experienced emotions are being manifested in speech. In fact the linguistic expression of emotions has to do with pragmalinguistic approach to language phenomena since the conveyance of emotions is necessarily linked with the perlocutionary level. Hence, in order to analyze the role of emotions in speech, expressive speech acts should be taken into consideration since expressives are those kinds of speech acts that 
state what the speaker feels: apologizing, thanking, congratulating, condoling, welcoming, deploring, and objecting. They express psychological states and can be statements of pleasure, pain, joy, sorrow, etc. Thus, we see that the emotional state of the speaker plays an irreplaceable and important role which is undoubtedly reflected in his or her speech (Yule 1996:53-54).

As we know, spoken language is not a ready-made or artificially created unit; it is something natural, created spontaneously so that to some degree it truly reflects our emotional world. Actually, in everyday communication the speakers not only exchange ideas, code and decode information, urge the hearer to do something but also convey via language means their feelings and emotions which, as it follows from our earlier discussions, are very complicated. The investigation of the expression of emotions is not a very easy task. In everyday communication all of us, to some extent, make use of different relevant parameters in order to make our speech more expressive: e.g. pitch, amplitude, voice quality, pause, etc. Prosody is the main constitutive cue of emphatic speech-style, alongside lexical devices, such as intensifying lexical items and syntactic devices.

In fact people try to make their speech expressive so that to have a better impact on the audience, to gain a better opportunity to achieve their desired positive or negative perlocutionary effect. For this very reason, they often make use of diverse function words, called intensifiers, which amplify the meaning of a whole sentence or only some part of it, and, particularly, the emotional content. Actually, normal English conversation abounds in a number of intensifiers which may be expressed by various parts of speech. Intensifiers constitute a large group of words belonging to different parts of speech, mostly adverbs, sometimes adjectives and particles homonymous with adverbs. They usually modify or intensify the word (or sometimes a phrase) immediately following them and serve to emphasize or restrict the meaning of this word (or phrase) (Buzarov 1998:316). The list is fairly long, and we create new intensifiers frequently, especially as slang. The common intensifiers are very, quite, really, pretty, too, fairly, more, rather, most, still, even, much, somewhat, not so, ever so, as well as many others. For instance, He's too awful, She's awfully attractive, It's pretty late. Belonging to the nonstandard language are the intensifying adjectives awful and real and the like, (I've got an awful bad cold, She was real nice to us). There exists yet another class of intensifiers, slang intensifiers, which are used by students and are constantly renewable. The intensifier wicked was in vogue a short time ago on many campuses (That was a wicked bad exam). Another intensifier which is also being heavily overworked these days is the intensifying adjective outstanding (She has an outstanding new car). And it should also be mentioned that as time passes, with the development of technology or due to some other extra-linguistic factors, new intensifiers (particularly when talking about colloquial language) come into being, whereas some older ones tend to fade away. In addition, sometimes intensifiers may be combined, so that to express much more reinforced meaning as damn a lot, an awful lot, very much and so on. Let us examine a case of positive intensification achieved by the combination of two intensifiers: 
"I know what you mean," said Anne Elizabeth, ruffling up his hair.

"You're an artist, Dick, and I love you very much ... you're my poet, Dick."

(John Dos Passos “U.S.A.”, Part 2, 1960:325)

In this passage Anne Elizabeth expresses her positive emotions, i.e. love, caring, warmth, tenderness, etc., towards her beloved person. To give extra emotive emphasis to her expressive speech act, she uses the intensifying adverb very, followed by the other adverb much. In the next example by means of combining several intensifiers reinforced negative meaning is implied:

"You sick?" a man asked Fuselli.

"Naw, I'm not sick; but Sarge sent me to get some stuff for some guys that's

too sick to move."

"An awful lot o' sickness on this boat."

(John Dos Passos “Three Soldiers”, 1921:47)

The example well demonstrates a case of negative emotive emphasis used in conversational English. The speakers are worried about the health of people on board. As we know during war time people experience negative emotions connected with a lot of factors, mainly with the health state of the soldiers; consequently those very negative emotions are actually expressed in speech. The second speaker reinforces the meaning of sick by attaching the intensifier too to it. The last speaker by combining different intensifying means, i.e. $a w f u l+a$ lot of, gives extra emotive emphasis to his representative speech act, which also implies negative emotions showing worry and concern. Generally, the implications of this speech event are negative.

\section{Positive Intensification Achieved via Intensifiers Having Negative Connotations}

There is a curious pattern of intensification that uses negative words to intensify positive ones. This class of intensifiers includes such adverbs as: awfully, dreadfully, fearfully, terribly, crazily, ridiculously, insanely, horribly, hideously, etc. Thus, for instance:

She is dreadfully beautiful.

What an insanely good idea!

What actually is happening here is that many strong emotions are negative, so when using them in a positive context the intensity of emotion, though being negative, shows that the real meaning is positive, i.e. an additional effect achieved through combining negative and positive words in the same sentence, creates confusion. The disclosure of the meaning greatly depends on the context, the extralinguistic reality, the relationship between the speakers, as well as some other extralinguistic factors. Let us consider the following examples: 
He interrupted her by starting to play again. As he played without looking at her, he felt that her eyes were fixed on him, that she was standing tensely behind him. Her hand touched his shoulder. He stopped playing.

"Oh, I am dreadfully sorry," she said.

"Nothing. I am finished."

(John Dos Passos “Three Soldiers”, 1921:346)

We may guess that in this speech event the young lady feels a bit embarrassed, timid, and guilty for disturbing the person who was playing the piano. This implies that she experiences negative emotions. The intensifying adverb dreadfully modifies the word sorry giving negative emotive emphasis to the act of apologizing. Accordingly, the phrase to be dreadfully sorry is equal to the phrase to be sorry very much which itself is an intensified expression owing to very much. In the next example we witness positive evaluation achieved via a word which itself bears a negative meaning:

She stepped over and took his arm. "Let's go in," she said. "The surf scares me, but it's terribly beautiful..."

(John Dos Passos “U.S.A.”, Part 3, 1960:70)

Here the character performs an expressive speech act on her evaluation of the surf. We observe a clash of two opposite poles which in result, creates confusion. On the one hand she feels scared but on the other hand she admires the beauty of the surf. It is this very clash of meanings that generates the actual intensified positive meaning. In fact, the adverb terribly intensifies the meaning of the adjective beautiful. In the next example we may detect another case of intensification achieved via the adverb crazily used to express positive emotions:

She sat down rather stiffly in the straight-backed armchair beside the fire.

"How pretty the fire is," she said.

"Jeanne, I think I'm crazily in love with you," said Andrews in an excited voice.

(John Dos Passos “Three Soldiers”, 1921:360)

Here, as it can obviously be guessed, the speakers are experiencing positive emotions like love, care, affection and the like. Thus, the speaker uses the intensifying adverb crazily to reinforce the actual positive implication of the statement and to stress the state of being in love.

Sometimes intensification is done deliberately but with the opposite intent. This use of sarcasm may be done against another person or may be used in a more ironic sense about this or that particular situation. For example, Oh, very clever! (actually meaning rather stupid) is equal to the imperative sentence How clever! that can also be used in negative sense. 
As a generalization we can state that people when undergoing very strong emotions do not manage to control the felt emotion or minimize its degree and consequently express those very emotions in speech. Moreover, they often tend to look for ways to emphasize how special the subject under discussion is. So they make use of different intensifiers and sometimes even exaggerate the display of their emotions on purpose to be able to change the listeners' opinion via their utterances, in other words, to have an emotive impact on the audience. Actually, with the help of intensifiers one may suggest to the listeners what emotions they should feel. When we speak emotionally, the other person has to consider the expressed emotions and hence, begins to feel them. In the same way, intensifiers may be used to reduce the natural emotional content of a sentence or some part of it. For this very purpose different structural means can be used (de-intensification, intensification, approval of the statements, etc.). Thus, while performing expressive speech acts people use different ways of intensifying the meaning of the whole sentence or some part of it, particularly the emotional content. Consequently we come to think that the role of emotions in speech should not be underestimated, since far too much of what happens in the process of communication occurs on the emotional level.

\section{Notes:}

1. The Arousal of Emotion (Edward J. Murray 1964: 51-56) maintains that emotions are aroused by a variety of innate stimulus patterns, learned stimuli and social situations. Firstly, he speaks about innate emotional arousal. For example, the emotion of fear can be produced in an animal, a child, or an adult by nearly any sudden and intense stimulus innately. Secondly, he claims that growing up both humans and animals may be afraid of much more things. A large part of the introduction of new fears and the elimination of old ones depends on learning. Murray states that this phenomenon is known in psychology as learned emotional arousal. According to him, another important factor in the arousal of emotion is one's personal threat. In this case emotional arousal depends on some of sort of personal evaluation of the threat, on a threat to something of personal importance.

2. Andersen and Guerrero (1998) divide their book on emotions into "The 'Dark Side' of Emotions" (e.g., embarrassment, hurt, jealousy, anger, etc.) and "The 'Bright Side' of Emotions" (e.g., comforting, support, warmth, loving, etc.).

\section{References:}

1. Andersen, P.A., Guerrero, L.K. (1998) Principles of Communication and Emotion in Social Interaction. // Handbook of Communication and Emotion. San Diego: Academic Press.

2. Austin, J.L. (1962) How to Do Things with Words. Oxford: Oxford University Press.

3. Buzarov, V.V. (1998) Essentials of Conversational English Syntax. M.: Crone-press. 
4. Gilbert, M.A. (1999) Language, Words and Expressive Speech Acts. // Proceedings of the Fourth International Conference of the International Society for the Study of Argumentation. www.yorku.ca/gilbert/argthry/argthry/arg-papers/mag1999-langwds.pdf

5. Goleman, D. (1995) Emotional Intelligence. New York, Toronto, London, Sydney, Auckland: Bantam Books.

6. Grice, H.P. (1969) Utterer's Meaning and Intentions. // Philosophical Review. New York: Academic Press.

7. Leech, G.N. (1983) Principles of Pragmalinguistics. London: Longman.

8. Levinson, S.C. (1983) Pragmalinguistics. Cambridge: Cambridge University Press.

9. Murray, E.J. (1964) Motivation and Emotion. New Jersey: Prentice-Hall.

10. Volf, E.M. (1985) Funkcianalnaya Semantika Otsenki. M.: Nauka.

11. Wukmir, V.J. (1967) Emoción y Sufrimiento. Barcelona: Labor.

12. Yule, G. (1996) Pragmalinguistics. // Oxford Introductions to Language Study. Oxford, New York: Oxford University Press.

\section{Sources of data:}

1. Dos Passos, J. (1921) Three Soldiers. New York: Modern Library.

2. Dos Passos, J. (1960) U.S.A. Trilogy. Boston: Houghton Mifflin.

\section{Znıjqkph nkpn lunupnıu}

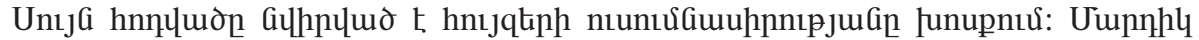

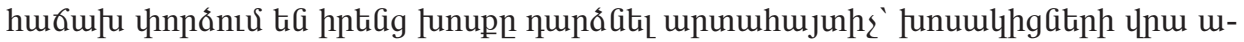

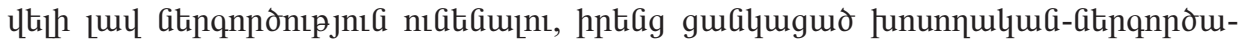

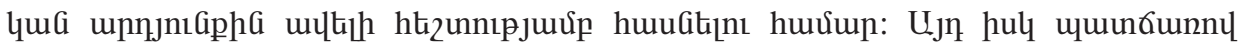

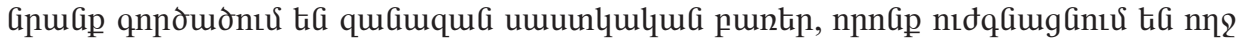

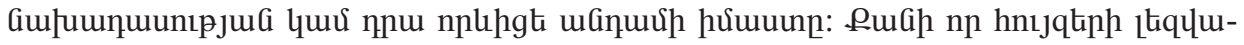

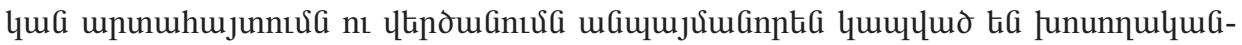

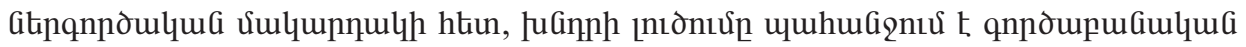
ununtignư: 